\title{
Abuso Sexual Infantil e Dinâmica Familiar: Aspectos Observados em Processos Jurídicos ${ }^{1}$
}

\author{
Luísa F. Habigzang \\ Sílvia H. Koller ${ }^{2}$ \\ Gabriela Azen Azevedo e \\ Paula Xavier Machado \\ Universidade Federal do Rio Grande do Sul
}

\begin{abstract}
RESUMO - O abuso sexual infantil é um problema de saúde pública, devido à elevada incidência epidemiológica e aos sérios prejuízos para o desenvolvimento das vítimas. A dinâmica desta forma de violência é complexa, envolvendo aspectos psicológicos, sociais e legais. Este estudo apresenta o mapeamento de fatores de risco para abuso sexual intrafamiliar identificados nos processos jurídicos do Ministério Público do Rio Grande do Sul - Brasil por violência sexual, no período entre 1992 e 1998. A análise de 71 expedientes apresenta o perfil das vítimas e a caracterização da violência sexual, dos agressores e das famílias. Os resultados apontaram que o desemprego, famílias reconstituídas, abuso de álcool e drogas, dificuldades econômicas e presença de outras formas de violência constituíram os principais fatores de risco associados ao abuso sexual. Tais resultados podem subsidiar ações preventivas e terapêuticas para situações de violência sexual contra crianças e adolescentes.
\end{abstract}

Palavras-chave: abuso sexual infantil; dinâmica familiar; fatores de risco.

\section{Sexual Abuse Against Children and Family Dynamics: Juridical Processes of a Public Prosecution Service}

\begin{abstract}
The sexual abuse of children is a public health issue, due to the high epidemic incidence and to the serious damages for the victims' development. The dynamic of this kind of violence is complex, involving psychological, social and legal aspects. This work maps the risk factors for intrafamiliar sexual abuse, identified in the juridical processes of the public prosecution service of Rio Grande do Sul - Brazil, during the period between 1992 and 1998. The analysis of 71 files shows the victims' profile and the characterization of the perpetrators, of the families and of sexual violence event. The results point that the unemployment, reconstituted families, alcohol and drug abuse, economical difficulties and other kinds of violence constituted the main risk factors associated to the sexual abuse. Such results can subsidize preventive and therapeutic actions against children and adolescents sexual violence.
\end{abstract}

Key words: sexual abuse; family dynamics; risk factors.

O abuso sexual contra crianças e adolescentes tem sido considerado um grave problema de saúde pública, devido aos altos índices de incidência e às sérias consequiências para o desenvolvimento cognitivo, afetivo e social da vítima e de sua família (Gonçalves \& Ferreira, 2002; Habigzang \& Caminha, 2004; Osofsky, 1995). Esta forma de violência pode ser definida como qualquer contato ou interação entre uma criança ou adolescente e alguém em estágio psicossexual mais avançado do desenvolvimento, na qual a criança ou adolescente estiver sendo usado para estimulação sexual do perpetrador. A interação sexual pode incluir toques, carícias, sexo oral ou relações com penetração (digital, genital ou anal). $\mathrm{O}$ abuso sexual também inclui situações nas quais não há contato físico, tais como voyerismo, assédio e exibicionismo. Estas interações sexuais são impostas às crianças ou aos adolescentes pela violência física, ameaças ou indução de

1 A equipe agradece ao Ministério Público do Estado do Rio Grande do Sul pelo apoio e disponibilização de material para a pesquisa.

2 Endereço: Rua Ramiro Barcelos, 2600, Sala 104, Porto Alegre, RS, Brasil 90035-003.E-mail: cep_rua@ufrgs.br sua vontade. (Azevedo \& Guerra, 1989; Thomas, Eckenrode \& Garbarino, 1997).

O abuso sexual também pode ser definido, de acordo com o contexto de ocorrência, em diferentes categorias. Fora do ambiente familiar, o abuso sexual pode ocorrer em situações nas quais crianças e adolescentes são envolvidos em pornografia e exploração sexual (Amazarray \& Koller, 1998; Koller, Moraes \& Cerqueira-Santos, 2005). No entanto, a maioria dos abusos sexuais cometidos contra crianças e adolescentes ocorre dentro de casa e são perpetrados por pessoas próximas, que desempenham papel de cuidador destas. Nesses casos, os abusos são denominados intrafamiliares ou incestuosos (Braun, 2002; Cohen \& Mannarino, 2000a; Habigzang \& Caminha, 2004; Koller \& De Antoni, 2004). Dessa forma, as relações sexuais, mesmo sem laços de consangüinidade, envolvendo uma criança e um adulto responsável (tutor, cuidador, membro da família ou familiar à criança) são consideradas incestuosas (Azevedo, Guerra \& Vaiciunas, 1997; Cohen \& Mannarino, 2000a; Thomas \& cols., 1997). Isto inclui madrastas, padrastos, tutores, meioirmãos, avós e até namorados ou companheiros que morem junto com o pai ou a mãe, caso eles assumam a função de 
cuidadores (Forward \& Buck, 1989). A familiaridade entre a criança e o abusador envolve fortes laços afetivos, tanto positivos quanto negativos, colaborando para que os abusos sexuais incestuosos possuam maior impacto cognitivocomportamental para a criança e sua família (Furniss, 1993; Habigzang \& Caminha, 2004).

O abuso sexual intrafamiliar é desencadeado e mantido por uma dinâmica complexa. Tal dinâmica envolve dois aspectos que se apresentam interligados: a "Síndrome de Segredo", que está diretamente relacionada com a psicopatologia do agressor (pedofilia) que, por gerar intenso repúdio social, tende a se proteger em uma teia de segredo, mantido às custas de ameaças e barganhas à criança abusada; e a "Síndrome de Adição" caracterizada pelo comportamento compulsivo do descontrole de impulso frente ao estímulo gerado pela criança, ou seja, o abusador, por não se controlar, usa a criança para obter excitação sexual e alívio de tensão, gerando dependência psicológica e negação da dependência (Furniss, 1993). Além disso, outras formas de violência intrafamiliar podem estar associadas com o abuso sexual. Muito comumente, as crianças e adolescentes vítimas de abusos sexuais no contexto familiar são também vítimas de negligência, abusos emocionais e físicos. Isto se confirma através dos relatos das vítimas que revelam as ameaças e agressões físicas sofridas durante o abuso sexual, bem como as sentenças depreciativas utilizadas pelo agressor e a falta de amparo e supervisão dos cuidadores (De Antoni \& Koller, 2000a; Habigzang \& Caminha, 2004; Koller, 1999).

As famílias incestuosas apresentam relações interpessoais assimétricas e hierárquicas, nas quais há uma desigualdade e/ou uma relação de subordinação (Koller, 1999). Alguns fatores de risco vêm sendo constantemente verificados em famílias incestuosas. Estes são: pai e/ou mãe abusados ou negligenciados em suas famílias de origem; abuso de álcool e outras drogas; papéis sexuais rígidos; falta de comunicação entre os membros da família; autoritarismo; estresse; desemprego; indiferença; mãe passiva e/ou ausente; dificuldades conjugais; famílias reestruturadas (presença de padrasto ou madrasta); isolamento social; pais que sofrem de transtornos psiquiátricos; doença, morte ou separação do cônjuge; mudanças de comportamento da criança, incluindo conduta hipersexualizada, fugas do lar, diminuição no rendimento escolar, uso de drogas e conduta delinqüente (Koller \& De Antoni, 2004; Thomas \& cols., 1997).

O abuso sexual pode afetar o desenvolvimento de crianças e adolescentes de diferentes formas, uma vez que algumas apresentam efeitos mínimos ou nenhum efeito aparente, enquanto outras desenvolvem graves problemas emocionais, sociais e/ou psiquiátricos (Heflin \& Deblinger, 1996/1999; Saywitz, Mannarino, Berliner \& Cohen, 2000). O impacto do abuso sexual está relacionado a fatores intrínsecos à criança, tais como, vulnerabilidade e resiliência (temperamento, resposta ao nível de desenvolvimento neuropsicológico) e a existência de fatores de risco e proteção extrínsecos (recursos sociais, funcionamento familiar, recursos emocionais dos cuidadores e recursos financeiros, incluindo acesso ao tratamento). Algumas consequiências negativas são exacerbadas em crianças que não dispõem de uma rede de apoio social e afetiva (Brito \& Koller, 1999; Saywitz \& cols., 2000). Os fatores que influenciam o impacto do abuso sexual são: saúde emocional prévia, crianças com saúde emocional positiva antes do abuso tendem a sofrer menos efeitos negativos; tipo de atividade sexual, alguns dados sugerem que formas de abuso mais intrusivas, como a penetração, resultam em mais conseqüências negativas; duração e frequiência dos episódios abusivos; reação dos outros, a resposta negativa da família ou dos pares à descoberta do abuso acentuam efeitos negativos (família, amigos e juízes atribuindo a responsabilidade à criança); dissolução da família depois da revelação; criança responsabilizando-se pela interação sexual; e, quando a vítima recebe recompensa pelo abuso e o perpetrador nega que o abuso aconteceu (Amazarray \& Koller, 1998; Deblinger \& Heflin, 1992/1995; Gabel, 1997; Mattos, 2002; Rouyer, 1997).

Apesar da complexidade e da quantidade de variáveis envolvidas no impacto do abuso sexual na criança, esta experiência é considerada um importante fator de risco para o desenvolvimento de psicopatologias (Saywitz \& cols., 2000). A literatura aponta que crianças ou adolescentes podem desenvolver quadros de depressão, transtornos de ansiedade, alimentares, dissociativos, hiperatividade e déficit de atenção e transtorno de personalidade borderline. Entretanto, a psicopatologia decorrente do abuso sexual mais citada é o transtorno do estresse pós-traumático (Cohen, Mannarino \& Rogal, 2001; Duarte \& Arboleda, 2004; Habigzang \& Caminha, 2004; Heflin \& Deblinger, 1996/1999). Além disso, estas podem apresentar crenças disfuncionais envolvendo sentimentos de culpa, diferença em relação aos pares e desconfiança (Cohen \& Mannarino, 2000b).

Alguns estudos epidemiológicos têm sido desenvolvidos com os objetivos de investigar a incidência e a prevalência do abuso sexual, bem como analisar indicadores psicológicos e sociais associados a este fenômeno. Os resultados têm apontado que a maioria dos abusos sexuais contra crianças e adolescentes ocorre dentro das casas da vítima e configuram-se como abusos sexuais incestuosos, sendo que o pai biológico e o padrasto aparecem como principais perpetradores. Ocorre, também, uma maior prevalência em meninas, principalmente entre os abusos incestuosos. A idade de início é bastante precoce, sendo que a maioria se concentra entre os 5 e os 8 anos de idade. A mãe é a pessoa mais procurada na solicitação de ajuda e a maioria dos casos é revelada pelo menos um ano depois do início do abuso sexual (Braun, 2002; Cohen, 1997; Caminha, Habigzang \& Bellé, 2003; De Lorenzi, Pontalti \& Flech, 2001; Kristensen, Oliveira \& Flores, 1999). Estes resultados são relevantes para o desenvolvimento de políticas públicas eficazes para prevenção e tratamento.

O presente estudo visa a contribuir com tais objetivos, mapeando fatores de risco para abuso sexual intrafamiliar identificados nos processos jurídicos do Ministério Público Estadual do Rio Grande do Sul/Brasil. Dessa forma, serão apresentados os resultados mais significativos da análise realizada nos processos jurídicos por violência sexual, no período entre 1992 e 1998. A análise apresenta aspectos do perfil das vítimas, bem como a caracterização da violência sexual, dos agressores e das famílias. Tais resultados podem subsidiar ações de caráter preventivo e de intervenção em situações de violência sexual contra crianças e adolescentes. 


\section{Método}

Foi realizada uma análise de documentos a partir de todos os processos de casos denunciados de violência sexual ajuizados pelas Promotorias Especializadas na Infância e na Juventude de Porto Alegre - Ministério Público Estadual do Rio Grande do Sul - entre 1992 e 1998, num total de 71 expedientes e 94 vítimas, uma vez que algumas vítimas constavam no mesmo expediente por pertencerem à mesma família.

\section{Material}

Foi utilizada uma ficha de dados ${ }^{3}$, elaborada pela equipe de pesquisa, para coletar informações relacionadas à vítima, à violência sexual, ao agressor, à família e às instituições que constituem a rede de encaminhamentos em cada caso (por ex., Conselho Tutelar, Ministério Público e Juizado da Infância e Juventude), bem como outras instituições (delegacias, hospitais, profissionais, etc.).

\section{Procedimentos}

Cada processo dos casos de violência sexual ajuizado no período foi analisado por uma pesquisadora capacitada do Centro de Estudos Psicológicos sobre Meninos e Meninas de Rua (CEP-RUA), que preencheu a ficha de dados relativa, uma vez que foi necessário interpretar as informações contidas nos expedientes. As fichas de dados foram conferidas uma a uma por outra pesquisadora e, em casos de dúvidas, o instrumento foi analisado por uma terceira pesquisadora, até a obtenção de consenso por discussão. Não houve falta de consenso nos casos em que apareceram discrepâncias iniciais.

\section{Resultados e Discussão}

\section{Perfil da vítima}

As crianças e adolescentes vítimas de abuso sexual eram, na maioria dos casos, do sexo feminino (80,9\%), enquanto que apenas $19,1 \%$ das vítimas eram do sexo masculino. A idade de início dos abusos concentrou-se em três faixas etárias, sendo que $10,6 \%$ das crianças apresentavam idade entre 2 e 5 anos, 36,2\% destas tinham entre 5 e 10 anos e $19,1 \%$ tinham entre 10 e 12 anos. A maioria das crianças $(26,6 \%)$ freqüentava o ensino fundamental no início das agressões. A idade da denúncia concentrou-se na adolescência, uma vez que $42,6 \%$ apresentavam idade entre 12 e 18 anos quando a situação abusiva foi delatada. Os demais casos foram denunciados quando a vítima tinha entre 1 e 5 anos (14,9\%), 5 a $10 \operatorname{anos}(20,2 \%)$ e 10 a $12(22,3 \%)$.

Estes dados estão em consonância com os estudos epidemiológicos sobre abuso sexual infantil (Finkelhor, 1994; Kristensen \& cols., 1999) que revelam que meninas são vítimas de abusos sexuais em maior freqüência do que meninos, principalmente, no ambiente familiar. A literatura especiali-

3 Esta ficha está disponível com a equipe de pesquisa. zada aponta que uma em cada quatro meninas e um em cada 10 meninos é vítima de violência sexual antes de completar 18 anos. Além disso, estes resultados revelam um aspecto importante da dinâmica do abuso sexual, a maioria dos casos é mantida em segredo por mais de um ano. Este fato ocorre devido a dois fatores: a Síndrome de Segredo e a Síndrome de Adição, conforme descritos na introdução (Furniss, 1993). O abuso sexual é caracterizado por uma progressão ascendente que inicia quando a criança é ainda muito pequena (5 a 10 anos nesta pesquisa) através de carícias mais sutis e torna-se mais explícito à medida que a criança cresce, ocorrendo a manipulação de genitais até relações sexuais orais ou genitais, freqüentemente na adolescência. Os abusos são mantidos em segredo, devido às ameaças e barganhas do abusador e aos sentimentos de vergonha e medo da vítima (Furniss, 1993; Habigzang \& Caminha, 2004).

O fim da violência sexual e o início do processo jurídico dependem do relato das vítimas, uma vez que na maioria dos casos não há provas materiais deste crime. Nos casos estudados, a situação de abuso sexual foi confirmada pela maioria das vítimas $(88,3 \%)$ para diferentes instituições como Conselho Tutelar (47\%), Juizado da infância e Juventude $(39,8 \%)$, mãe $(36,1 \%)$, delegacia de polícia $(31,3 \%)$, Ministério Público (26,5\%), entre outras. Apenas $11,7 \%$ das vítimas não confirmaram a agressão sexual. A maioria das vítimas residia com os pais e irmãos $(36,6 \%)$ ou com o padrasto, mãe e irmãos $(23,4 \%)$ na época da agressão.

Algumas características pessoais consideradas como positiva e negativa das vítimas também foram obtidas em informações registradas nos documentos, pelos técnicos (psicólogos, juízes, conselheiros tutelares) que atenderam os casos. As principais características consideradas positivas foram atitude pessoal com relação ao abuso $(66,2 \%)$, interesse da vítima pelos estudos $(29,4 \%)$, capacidade em se comunicar $(19,1 \%)$, estratégias eficazes de enfrentamento $(16,2 \%)$, aparência física limpa e agradável $(11,8 \%)$ e afetividade $(8,8 \%)$. Por outro lado, características pessoais tais como atitude negativa diante do técnico $(76,5 \%)$, distúrbios do desenvolvimento (16,2\%), afeto/vínculos negativos $(10,3 \%)$, aparência física carente de cuidados $(7,4 \%)$, falta de limites $(4,4 \%)$ e agressividade confrontativa $(4,4 \%)$ foram consideradas pelos técnicos como negativas.

O uso de álcool e de outras drogas pelas vítimas foi outro fator mapeado. Quanto ao uso de álcool foi constatado que em 3,2\% dos casos apresentavam este comportamento, enquanto que em relação ao uso de outras drogas foi verificado que em $11,7 \%$ dos casos já haviam utilizado algum tipo de droga. Entre as drogas utilizadas, as mais freqüentes foram loló $(27,3 \%)$, maconha $(27,3 \%)$ e cola $(18,2 \%)$. O cigarro também foi citado, além de sustâncias químicas ingeridas como tentativa de suicídio ou como tentativa de evitar gravidez ou provocar aborto. Somente 18 casos não relataram explicitamente problemas de saúde decorrentes da agressão. Os problemas identificados nestes casos foram, principalmente, mentais e psicológicos $(33,3 \%)$, problemas respiratórios $(27,8 \%)$, problemas decorrentes de negligência com a higiene $(16,7 \%)$, problemas viróticos ou bacteriológicos $(11,1 \%)$, HIV $(11,1 \%)$ e congênitos $(11,1 \%)$. Estes resultados corroboram os estudos sobre o impacto negativo do abuso sexual para o desenvolvimento cognitivo, afetivo e social de crianças 
e de adolescentes. As vítimas freqüentemente desenvolvem sintomas psiquiátricos, bem como apresentam alterações comportamentais que incluem delinqüência e drogadição (Cohen \& cols., 2001; Edwards, Anda, Nordenberg, Felitti, Williamson \& Wright, 2001; Rouyer, 1997).

A percepção das vítimas com relação ao perpetrador foi encontrada em alguns processos $(58,5 \%)$. A maioria das crianças e dos adolescentes expressava desejo de ficar afastada do agressor $(41,8 \%)$ e sentia medo deste $(38,2 \%)$. Com relação à percepção da agressão, $31,9 \%$ dos documentos analisados apresentaram informações e dentre estas, as crianças afirmaram não ser favorável à situação, ou seja, não consentiram, buscando evitá-la, ou manifestaram sua falta de compreensão quanto à experiência abusiva. Os sentimentos de medo, raiva e vergonha da vítima em relação ao perpetrador são comuns, principalmente em casos de abuso sexual intrafamiliar, uma vez que a relação de confiança e o vínculo afetivo são rompidos devido à violência. Com relação à situação abusiva, os estudos apontam que as crianças desenvolvem crenças distorcidas, tais como percepção de que são culpadas pelo ocorrido, de que são ruins e diferentes de outras crianças com a mesma idade, bem como apresentam alterações na percepção quanto à confiança interpessoal (Duarte \& Arboleda, 2004; Habigzang \& Caminha, 2004; Mannarino, Cohen \& Berman, 1994).

\section{Violência sexual}

A violência sexual foi denunciada pela mãe da vítima em $37,6 \%$ dos casos, pela própria vítima em $29 \%$ dos casos, por outros parentes, em 15,1\%, e, por instituições, tais como, escola, hospital e departamento de polícia em $6,5 \%$ dos casos. Entretanto, em $61,7 \%$ dos casos, alguém informou que já sabia da situação abusiva e não denunciou. Destes casos, as pessoas que tinham conhecimento anterior da violência eram a mãe $(55,2 \%)$, irmãos $(54,3 \%)$, parentes $(22,4 \%)$, pai $(5,2 \%)$, escola $(1,7 \%)$ e outros $(10,3 \%)$. Estes dados revelam a dificuldade que a família e a sociedade ainda apresentam para denunciar situações de suspeita ou confirmação de abuso sexual contra crianças e adolescentes aos órgãos de proteção. Embora a denúncia seja um procedimento determinado por lei (Estatuto da Criança e do Adolescente, Art. 245, Lei Federal no 8069/1990), a subnotificação é uma realidade em nosso país (Gonçalves \& Ferreira, 2002). Esta subnotificação ocorre devido a vários fatores, tais como os sentimentos de culpa, vergonha e tolerância da vítima; a relutância de alguns médicos em reconhecê-lo e relatá-lo; a insistência de tribunais por regras estritas de evidência e o medo da dissolução da família, se for descoberto o abuso (Furniss, 1993; Zavaschi, Telelbom, Gazal \& Shansis, 1991). Além disso, o trabalho nesse campo ainda é fragmentado, desorganizado e, em geral, metodologicamente difuso. Há um despreparo generalizado envolvendo desde os profissionais da área de saúde, educadores e juristas até as instituições escolares, hospitalares e jurídicas, em manejar e tratar adequadamente os casos surgidos (Amazarray \& Koller, 1998).

Em 89 dos 94 documentos analisados havia informação sobre o encaminhamento adotado. Entre os primeiros encaminhamentos, destaca-se ao Conselho Tutelar $(40,4 \%)$, à polícia $(29,2 \%)$, à escola $(9 \%)$, ao hospital ou à unidade pública de saúde $(7,9 \%)$ e à instituição do bem-estar social $(6,7 \%)$. A violência sexual foi comprovada ou confirmada em 68 dos 94 casos investigados. Em 11 casos não houve confirmação e em 15 casos não havia informação suficiente para confirmação. A principal forma de comprovação ou confirmação da violência sexual foi o depoimento da vítima $(63,2 \%)$. Outras formas de comprovação consistiram em exames ginecológicos, laudos do Instituto Médico Legal e exame de corpo de delito $(32,4 \%)$, relato da mãe $(30,9 \%)$, avaliação psicológica $(27,9 \%)$ e depoimentos de outros familiares (25\%). Os indícios que se mostraram contra a ocorrência de violência sexual foram, principalmente, o depoimento do agressor $(48,2 \%)$, depoimento da mãe da vítima $(34,1 \%)$, laudos no instituto médico legal $(22,4 \%)$, depoimento da vítima $(18,8 \%)$ e ausência de exames médicos ou provas materiais $(14,1 \%)$. Estes resultados apontam outras dificuldades ainda encontradas nos casos de denúncia de violência sexual. Entre elas destacam-se a falta de capacitação dos profissionais que atuam nos órgãos de proteção à criança $\mathrm{e}$ ao adolescente para obter o relato da vítima sobre a situação abusiva, mesmo quando há indicadores evidentes do caso, bem como o desconhecimento da dinâmica do abuso para identificar fatores de risco. Além disso, as provas materiais são ainda exigidas por alguns juristas, que desconsideram que o abuso sexual pode não deixar evidências físicas, como nos casos de assédio, carícias e manipulação de genitais e exposição à pornografia. Dessa forma, uma avaliação psicológica criteriosa da vítima e da família pode ser uma importante evidência para a confirmação de casos nos quais há suspeita de abuso sexual (Koller \& De Antoni, 2004).

Outras violações dos direitos das crianças e dos adolescentes relacionados ao caso foram investigadas. Além da violência sexual intrafamiliar, foram constatados registros de violência física, violência psicológica e diferentes formas de negligência. Dos 91 casos, nos quais esta informação estava disponível, foi verificado que o perpetrador exercia, na maioria dos casos, a função parental. Estas violações foram denunciadas, principalmente, pela própria vítima, pela mãe, pelos irmãos e por vizinhos. A comorbidade, ou seja, a coexistência de diferentes formas de violência em famílias incestuosas tem sido freqüentemente apontada pelos pesquisadores da área (Cohen \& Mannarino, 2000a; Habigzang \& Caminha, 2004; Kellog \& Menard, 2003). A violência física e psicológica intrafamiliar contribui para a manutenção do abuso sexual em segredo, devido às ameaças do perpetrador e aos sentimentos de medo e de impotência da vítima e dos outros membros da família.

$\mathrm{O}$ ato de violência sexual foi descrito com mais detalhes em 77 casos. As principais categorias identificadas foram esfregar-se no corpo da vítima ou passar a mão pelo corpo (39\%), sexo vaginal $(28,6 \%)$, tirar as roupas $(27,3 \%)$, sexo anal $(24,7 \%)$, sexo oral $(19,5 \%)$, exibicionismo da genitália $(15,6 \%)$, assédio $(14,3 \%)$, masturbação da vítima pelo agressor e vice-versa (13\%) e obrigação de assistir relações sexuais de terceiros $(10,4 \%)$.

O principal contexto onde ocorreu a violência sexual foi a própria casa da vítima ( $66,7 \%$ dos casos), quando esta estava sozinha com o agressor. $\mathrm{O}$ tempo de duração da violência sexual foi informado em $62,8 \%$ dos documentos analisados e constatou-se que destes, $32,2 \%$ dos casos teve duração entre 
um e 11 meses e 67,8\% dos casos teve duração entre um e nove anos. Em 45,7\% dos casos havia informação sobre o número de vezes que a violência sexual ocorreu. Na maioria dos casos $(79,1 \%)$, a violência sexual ocorreu mais de uma vez e em $41,9 \%$ destes, a ocorrência era diária. Estes resultados estão em consonância com os estudos epidemiológicos nacionais e internacionais que apontam que cerca de $80 \%$ dos casos de abuso sexual contra crianças é perpetrado no contexto doméstico, tendo uma duração de mais de um ano (Braun, 2002; Kristensen \& cols., 1999; Thomas \& cols., 1997). Em 70,2\% dos casos investigados não há relato de ameaças. Entre os casos, nos quais foi verificado relato de ameaças, estas se referiam à morte, rompimento da relação, violência física com faca, chantagens, separação da mãe ou abrigamento da vítima. Em 11 casos foram descritas formas de violência física, tais como, socos, pontapés e tapas. Em 11 casos foi identificado, ainda, relato de atividades da vítima para cessar a violência. Nestes casos, as vítimas gritaram, fugiram ou empurraram o agressor. As principais condições psicológicas após a situação de abuso sexual das vítimas, conforme encontradas nos processos, foram problemas relacionados à sexualidade $(57,8 \%)$, manifestações emocionais $(42,2 \%)$, inibição afetiva e social (introversão ou isolamento) $(32,8 \%)$, sintomatologia psicológica $(29,7 \%)$, agressividade confrontativa $(21,9 \%)$, falta de limites $(20,3 \%)$, dificuldades na escola $(20,3 \%)$, tentativas de suicídio $(14,1 \%)$ e comportamentos delinquientes (infrações ou delitos) $(14,1 \%)$.

\section{Perfil do agressor}

Em 90, dos 94 documentos analisados, havia registro de características do agressor. Na maioria dos casos este era do sexo masculino $(98,8 \%)$ e tinha vínculos afetivos e de confiança com a vítima. Em 57,4\% dos casos, o agressor era pai da vítima e em $37,2 \%$ dos casos, este era padrasto ou pai adotivo desta. Estes resultados corroboram a literatura especializada que aponta que o abuso sexual contra crianças e adolescentes é perpetrado, na maioria dos casos, por cuidadores do sexo masculino. Este fenômeno pode ser compreendido por meio de aspectos sociais e culturais que envolvem a desigualdade, a dominação de gênero e de gerações (Gomes, Deslades, Veiga, Bhering \& Santos, 2002). A maioria dos agressores $(52,2 \%)$ tinha idade entre 31 e 40 anos. Verificam-se, ainda, informações disponíveis nos processos sobre características pessoais comumente apontadas como fatores de risco para violência sexual. Entre estas, as mais significativas são agressividade, problemas com álcool e outras drogas, transtornos mentais, rigidez, fanatismo religioso e possessividade (Furniss, 1993; Thomas \& cols., 1997). É importante salientar que estas características indicam maior probabilidade de violência, mas não podem ser consideradas em uma relação direta de causa e efeito.

A ocupação do agressor foi encontrada em 81 casos foi encontrado registro. Uma parte dos agressores estava empregada $(43,2 \%)$. Mas a maioria estava desocupada ou em trabalho eventual. Uma parte deles estava desempregada $(32,1 \%)$, fazendo biscates $(16 \%)$, aposentados $(6,2 \%)$ ou eram autônomos $(2,5 \%)$. O desemprego é um fator de risco para a violência intrafamiliar, uma vez que pode gerar estresse e conflito entre os membros da família. Além disso, o pai ou cuidador que exerce esta função fica como principal responsável pelas crianças durante a maior parte do tempo, oportunizando a ocorrência de abusos sexuais (Koller \& De Antoni, 2004; Thomas \& cols., 1997). O nível de escolaridade do agressor também pode ser considerado um fator de risco. Em apenas 32 casos analisados havia registro do nível de escolaridade do agressor, sendo que $40,6 \%$ destes tinha primeiro grau incompleto e $25 \%$ primeiro grau completo. Os demais eram analfabetos $(15,6 \%)$, tinham segundo grau incompleto ou completo $(15,6 \%)$ ou terceiro grau incompleto $(3,1 \%)$. Estes resultados apontam que a maioria dos agressores possuía baixo nível de escolaridade. Em 25 casos havia registro da religião do perpetrador e verificou-se que $36 \%$ destes eram católicos, $36 \%$ eram evangélicos, $16 \%$ eram espiritualistas, $4 \%$ não tinham religião e $8 \%$ eram de outras religiões (Mayer, 2003).

A situação conjugal do agressor no início e no final do expediente processual jurídico também foi mapeada. No início, a maioria dos agressores era casado ou vivia maritalmente $(75,3 \%)$ e ao final do processo, a maioria dos agressores estava separado (69,5\%). O uso de álcool e outras drogas foi investigado e verificou-se que 53,2\% dos agressores era usuário de álcool e 27,7\% destes abusava de alguma outra substância tóxica.

Em apenas 18 documentos analisados foram encontrados registros de alegações do agressor para cometer a violência sexual. Os principais motivos alegados foram percepção da vítima como pessoa adulta e capaz de ter relações sexuais $(31,3 \%)$, questões religiosas $(25 \%)$, deseja ser o responsável pela iniciação sexual da filha (25\%). Em 64 casos havia registro dos argumentos oferecidos para a defesa do agressor. Os principais argumentos foram negação de violência (56,3\%), calúnia da mãe por vingança, raiva, desavenças com o agressor $(17,2 \%)$, parentes e amigos induziram a vítima a denunciar para retirá-la de casa ou por detestarem o agressor $(14,1 \%)$, calúnia da vítima para não se submeter às ordens e regras do agressor $(10,9 \%)$, responsabiliza a vítima pela violência $(10,9 \%)$, responsabiliza outras pessoas pela violência sexual $(19,9 \%)$, mal entendido $(6,3 \%)$ e atribui os sintomas da violência ao afastamento da mãe do lar $(3,1 \%)$.

Verifica-se que a maioria dos agressores negou a violência sexual. Entre os agressores que confirmaram o abuso, constata-se que, tanto nos motivos alegados, quanto nos argumentos utilizados para defesa, estes atribuíram a culpa à vítima ou à outra pessoa (cônjuge, vizinhos, familiares). A negação do abuso ou culpabilização da vítima pelo agressor é um importante fator de risco para o desenvolvimento de problemas psicológicos na criança ou adolescente, principalmente, quando o perpetrador é um membro da família, uma vez que a relação de confiança é abalada (Deblinger \& Heflin, 1995; Furniss, 1993; Gabel, 1997; Mattos, 2002; Rouyer, 1997).

Também foi investigada a existência de outras vítimas nos mesmos processos. Foi verificado que em $37,2 \%$ dos casos, o agressor havia abusado sexualmente de outras pessoas no mesmo contexto doméstico. Estas vítimas foram irmãos da vítima, enteada, mãe, empregada ou outras crianças. Entretanto, na maioria dos casos $(80,9 \%)$, o agressor não apresentava antecedentes criminais. Entre os agressores que apresentavam antecedentes criminais, estes envolviam furtos $(44,4 \%)$, 
assassinatos $(33,3 \%)$, tráfico ou uso de drogas $(16,7 \%)$, lesão corporal $(11,1 \%)$, danos materiais $(5,6 \%)$ e ameaças $(5,6 \%)$. Estes dados apontam um problema importante para os profissionais que investigam suspeitas de abuso sexual. A maioria dos pedófilos não apresenta antecedentes criminais e as pessoas de sua convivência o descrevem como trabalhador, religioso e cuidador zeloso de sua família (Cohen \& Mannarino, 2000a; Furniss, 1993). Este perfil pode confundir os profissionais e levá-los a cometer o erro de considerar o relato da criança fantasioso diante da negação do agressor.

Por fim, foi constatado que em $19,1 \%$ dos casos analisados havia relato sobre a existência de outros agressores para a mesma vítima. Estes foram o tio $(33,3 \%)$, o patrão do pai $(27,8 \%)$, o pai $(16,7 \%)$, a mãe $(17,7 \%)$, o padrasto (16,7\%), um agressor desconhecido $(11,1 \%)$, o avô $(5,6 \%)$ e um grupo de estranhos na rua $(5,6 \%)$. Este resultado pode ser compreendido pelo comportamento hipersexualizado que muitas vítimas apresentam em decorrência do abuso sexual. Esta alteração do comportamento coloca crianças e adolescentes em situação de vulnerabilidade, potencializando a revitimização. Por esta razão, qualquer programa de tratamento a vítimas de violência sexual deve trabalhar terapeuticamente medidas de proteção para reduzir o risco de novas situações abusivas (Deblinger \& Heflin, 1995; Habigzang \& Caminha, 2004).

\section{Família}

Algumas características sobre as famílias das vítimas foram mapeadas. Do total de casos investigados, $83 \%$ aconteceram na própria família, concedendo à violência sexual um caráter intrafamiliar. Os pais foram os agressores em $79 \%$ dos casos (40 pais), seguidos pelos padrastos das vítimas (16). A configuração familiar modificou-se com a denúncia da violência sexual. Este fato é revelado pela análise da situação conjugal dos pais das vítimas antes e depois da denúncia. Antes da denúncia, $56,4 \%$ dos pais 'viviam' juntos, $42,6 \%$ 'viviam' separados e $1,1 \%$ dos casos não havia informação. Depois da denúncia, apenas $18,1 \%$ dos pais vivam juntos, enquanto que $79,8 \%$ vivam separados. Em $2,1 \%$ dos casos não havia informação.

A reorganização familiar é uma consequiência freqüente após a denúncia de abuso sexual. Isto ocorre porque a criança ou adolescente devem ser protegidos e esta proteção é realizada através do afastamento do agressor ou da própria vítima. $\mathrm{O}$ afastamento da vítima ocorre quando os familiares não conseguem se organizar para protegê-la. Nestes casos, a criança é abrigada ou sua guarda legal passa a ser de algum familiar não-abusivo. Trata-se de uma situação difícil para a vítima que tende a se sentir culpada pelo sofrimento de todos. Em um estudo realizado com 13 meninas vítimas de abuso sexual, todas relataram sentir culpa pelo sofrimento da mãe e dos irmãos quando o pai ou padrasto foi afastado do lar. Por outro lado, as meninas que foram abrigadas percebiam o fato de estarem em um abrigo como um castigo pelo abuso (De Antoni \& Koller, 2000b; Habigzang \& Caminha, 2004).

Outro aspecto importante da dinâmica familiar foi a presença de outros tipos de violência, tais como, violência física ou psicológica, negligência dos pais e uso de drogas. A violência apresentou-se como estratégia predominante nas práticas educativas dos pais. As proibições (em geral) foram notadas em $73 \%$ das famílias. Agressões físicas apareceram em $40,5 \%$ dos casos, enquanto que agressões verbais e terrorismo ocorreram em $21,6 \%$ deles. Em 10,8\% das famílias, os filhos assumiam o papel dos pais, revelando reversão hierárquica na família (De Antoni, 2005).

A situação financeira das famílias foi investigada e verificou-se que, em sua maioria, somente um dos cônjuges trabalhava. Estas moravam em residências precárias e poucas em imóvel próprio. Foi constatado que 39,6\% das famílias viviam em situação de pobreza. Embora o desemprego e as dificuldades econômicas sejam fatores de risco para a violência, é importante salientar que este é um fenômeno que ocorre em todos os níveis sociais, mas nem sempre chegam ao Ministério Público. Outra característica avaliada em relação às famílias foi o número de pessoas que as constituía. Esta característica apresentou uma alta variabilidade na população estudada, sendo que em $46,1 \%$ dos casos a família era composta por quatro a seis membros, $20,2 \%$ por sete a nove membros, $15,7 \%$ por 10 a 16 membros, $15,7 \%$ por três membros e $2,2 \%$ por dois membros.

A religião das famílias também foi mapeada. Predominaram, nesta ordem, as religiões católica $(30,4 \%)$, evangélica $(26,1 \%)$, afro ou umbanda $(21,7 \%)$ e adventista $(13 \%)$. Algumas famílias foram descritas no processo como sendo fanáticos religiosos ( $26,1 \%$ dos casos).

A negação da violência sexual por parte da família foi um fato frequiente. $\mathrm{O}$ agressor negou a violência sexual em $57,4 \%$, a mãe em $20,2 \%$, a vítima em $4,3 \%$, o pai em $3,2 \%$ e outros em 10,6\%. Em 29,8\% não havia esta informação. A mãe foi a principal protetora (59,4\% das famílias), seguida de outros $(25,5 \%)$ e de tios $(12,8 \%)$. É interessante salientar que, em 26,6\% dos casos, não houve quem protegesse a vítima. A principal forma de proteção adotada foi a denúncia $(78,3 \%)$. O afastamento da vítima do agressor ocorreu em $20,3 \%$ dos casos. Tentativas de impedir a ocorrência sexual $(15,9 \%)$ e outras pessoas assumirem a guarda da vítima $(10,1 \%)$ foram outras formas de proteção.

As ações tomadas pela família durante o conflito foram investigadas. Em 73,3\% delas, houve tentativas de proteção, enquanto que $41,1 \%$ negaram totalmente a violência sexual. $10 \%$ das famílias não conseguiram proteger as vítimas (respostas múltiplas). Entre as estratégias de organização da família no conflito, destacaram-se abrigamento ou colocação da vítima em famílias substitutas ou com familiares (50\%), mãe abandona o companheiro ou agressor $(34,5 \%)$, agressor é preso ou afastado do lar (31\%), mãe separa-se do agressor (19\%), vítima mantém contato com agressor $(16,7 \%)$, agressor ameaça a família $(15,5 \%)$, familiares e/ou vítima passam a defender o agressor (15,5\%), fuga das vítimas $(14,3 \%)$ e situação inicial de violência sexual permanece $(9,5 \%)$.

As reações da família, principalmente da mãe, frente à revelação da vítima são um importante fator para o desenvolvimento de sintomatologias psiquiátricas e alterações de comportamento na vítima. Quando a família demonstra credibilidade ao relato da criança e assume estratégias para protegê-la, esta se sente fortalecida e apresenta maiores recursos para enfrentar a experiência abusiva. Contudo, quando a reação da família é negativa e esta não oferece apoio social e afetivo, a vítima apresenta-se em situação de 
vulnerabilidade, podendo desenvolver problemas tais como isolamento social, depressão, pensamentos e tentativas de suicídio, ansiedade, entre outros (Cohen \& Mannarino, 2000b). Dessa forma, tanto a vítima, quanto a família necessitam de acompanhamento psicológico para compreender o que é abuso sexual e sua dinâmica, quais são suas conseqüências e como é possível evitar situações de violência. Além disso, a rede de atendimento desempenha um importante papel de proteção e apoio nos casos de violência sexual (Habigzang, Koller, Azevedo \& Machado, no prelo).

\section{Considerações Finais}

As informações coletadas a partir da análise dos processos jurídicos disponíveis no Ministério Público Estadual sobre os casos de violência sexual contra crianças e adolescentes permitiram compreender como estão sendo descritos os casos e suas dinâmicas nesta forma de violência e os fatores de proteção e de risco envolvidos no contexto familiar.

Os resultados revelaram que as meninas são vítimas de abuso sexual em maior freqüência quando comparadas com meninos. Além disso, a maior incidência desta forma de violência ocorreu quando as vítimas eram crianças (5 a 10 anos) e a revelação ocorreu, na maioria dos casos, apenas na adolescência. Dessa forma, a violência sexual foi mantida em segredo por anos, até que as vítimas conseguiram revelar os abusos ou algum adulto não-abusivo suspeitou e denunciou aos órgãos públicos. Os perpetradores da violência sexual foram, na maioria dos casos, homens que conviviam no ambiente doméstico da criança e possuíam uma relação de confiança e cuidado com esta.

O estudo também apontou que o ambiente familiar constituiu o principal contexto no qual as crianças e adolescentes foram vitimizados sexualmente. A literatura especializada aponta fatores de risco para a família incestuosa, que foram freqüentemente encontrados nos casos analisados. Entre os principais fatores de risco destaca-se a presença de padrasto na família, abuso de álcool ou drogas, desemprego, mãe passiva ou ausente, pais desocupados e cuidando dos filhos por longos períodos de tempo e dificuldades econômicas. Outro aspecto importante identificado nos casos analisados foi a presença de outras formas de violência no contexto familiar, tais como, negligência e abusos psicológicos e físicos contra as crianças, bem como violência física conjugal. Além disso, a revelação do abuso sexual demonstrou modificar a configuração familiar, uma vez que os dados apontam o rompimento das relações conjugais ou o afastamento da criança do convívio com os familiares.

Os resultados ainda apontaram que o perpetrador freqüentemente negou o abuso ou culpabilizou a vítima. Na maioria dos casos a mãe foi a principal figura protetiva, denunciando o caso aos órgãos de proteção à criança e ao adolescente. Entretanto, a exigência de provas materiais dificultou a comprovação do abuso em muitos casos. Dessa forma, as crianças são duplamente vitimizadas, primeiro pela dinâmica da família incestuosa e, segundo, pelas exigências jurídicas que desconsideram as dimensões psicológica e social que configuram tal fenômeno. Portanto, os resultados sugerem a necessidade urgente de capacitação profissional para identificar e diagnosticar os casos de violência sexual, bem como de promover intervenções preventivas e terapêuticas para as crianças e adolescentes e para suas famílias.

\section{Referências}

Amazarray, M. R. \& Koller, S. H. (1998). Alguns aspectos observados no desenvolvimento de crianças vítimas de abuso sexual. Revista de Psicologia Reflexão e Crítica, 11(3), 546-555.

Azevedo, M. A. \& Guerra, V. N. A. (1989). Crianças vitimizadas: a síndrome do pequeno poder. São Paulo: IGLU.

Azevedo, M. A., Guerra, V. N. A \& Vaiciunas, N. (1997). Incesto ordinário: a vitimização sexual doméstica da mulher-criança e suas consequiências psicológicas. Em M. A. Azevedo \& V. N. A. Guerra (Orgs.), Infância e violência doméstica: Fronteiras do conhecimento (pp. 195-209). São Paulo: Editora Cortez.

Braun, S. (2002). A violência sexual infantil na família: do silêncio à revelação do segredo. Porto Alegre: Age.

Brito, R. C. \& Koller, S. H. (1999). Redes de apoio social e afetivo e desenvolvimento. Em A. M. Carvalho (Org.), O mundo social da criança: natureza e cultura em ação (pp. 115-130). São Paulo: Casa do Psicólogo.

Caminha, R. M., Habigzang, L. F. \& Bellé, A. (2003). Epidemiologia de abuso sexual infantil na clínica escola PIPAS/UNISINOS. Em Caderno de Extensão UNISINOS IV, 129-142.

Cohen, C. (1997). O incesto. Em M. A. Azevedo \& V. N. A. Guerra (Orgs.), Infância e violência doméstica: Fronteiras do conhecimento (pp. 212-225). São Paulo: Editora Cortez.

Cohen, J.A. \& Mannarino, A. P. (2000a). Incest. Em R. T. Ammerman \& M. Hersen (Orgs.), Case studies in family violence (pp. 209-229). New York: Klewer Academic/ Lenum Publishers.

Cohen, J. A. \& Mannarino, A. P. (2000b). Predictors of treatment outcome in sexually abused children. Child Abuse \& Neglect, 24(7), 983-994.

Cohen, J. A, Mannarino, A. P. \& Rogal, S. (2001). Treatment practices for childhood posttraumatic stress disorder. Child Abuse \& Neglect, 25, 123-135.

De Antoni, C. \& Koller, S. H. (2000a). Vulnerabilidade e resiliência familiar. Um estudo com adolescentes que sofreram maus tratos intrafamiliares. Psico, 31, 39-66.

De Antoni, C. \& Koller, S. H. (2000b). A visão sobre família entre as adolescentes que sofreram violência intrafamiliar. Estudos de Psicologia, 5, 347-381.

De Antoni, (2005). Coesão e Hierarquia em famílias com história de abuso físico. Tese de Doutorado, Universidade Federal do Rio Grande do Sul, Porto Alegre.

Deblinger, E. \& Heflin, A. H. (1995). Abuso sexual infantil. Em F. M. Dattilio \& A. Freeman (Orgs.), Estratégias cognitivocomportamentais para intervenção em crises: tópicos especiais (pp. 229-253, M. Lopes e M. Carbajal, Trad.). São Paulo: Editorial Psy. (Original publicado em 1992)

De Lorenzi, D. R. S., Pontalti, L. \& Flech, R. M. (2001). Maus tratos na infância e adolescência: análise de 100 casos. Revista Científica da AMECS, 10(1), 47-52.

Duarte, J. C. \& Arboleda, M. R. C. (2004). Sintomatologia, avaliação e tratamento do abuso sexual infantil. Em V. Caballo (Org.), Manual de psicologia clínica infantil e do adolescente: Transtornos gerais (pp. 293-321). São Paulo: Santos.

Edwards, V. J., Anda, R. F., Nordenberg, D. F, Felitti, V. J, Williamson, D. F \& Wright, J. A. (2001). Bias assessment for 


\section{F. Habigzang e cols.}

child abuse survey: Factors affecting probability of response to a survey about chilhood abuse. Child Abuse \& Neglect, 25, 307-312.

Estatuto da Criança e do Adolescente (1990). Diário Oficial da União. Lei Federal no 8.069, de 13 de julho de 1990, Brasília, DF.

Finkelhor, D. (1994). The international epidemiology of child sexual abuse. Child Abuse \& Neglect, 18, 409-417.

Forward, S. \& Buck, C. A. (1989). A traição da inocência: o incesto e sua devastação. Rio de Janeiro: Rocco.

Furniss, T. (1993). Abuso sexual da criança: uma abordagem multidisciplinar. falta tradutor Porto Alegre: Artes Médicas.

Gabel, M. (1997). Crianças vítimas de abuso sexual. falta tradutor São Paulo: Summus Editorial.

Gomes, R., Deslades, S. F., Veiga, M. M, Bhering, C. \& Santos, J. F. C. (2002). Por que as crianças são maltratadas? Explicações para a prática de maus-tratos infantis na literatura. Cadernos de Saúde Pública,18(3), 707-714.

Gonçalves, H. S. \& Ferreira, A. L. (2002). A notificação da violência intrafamiliar contra crianças e adolescentes por profissionais da saúde. Caderno de Saúde Pública, 18(1), 315-319.

Habigzang, L. F. \& Caminha, R. M. (2004). Abuso sexual contra crianças e adolescentes: Conceituação e intervenção clínica. São Paulo: Casa do Psicólogo.

Habigzang, L. F., Koller, S. H., Azevedo, G. A. \& Machado, P. X. (no prelo). Fatores de risco e de proteção na rede de atendimento a crianças e adolescentes vítimas de violência sexual. Psicologia Reflexão e Crítica.

Heflin, A. H. \& Deblinger, E. (1999). Tratamento de um adolescente sobrevivente de abuso sexual na infância. Em M. Reinecke, F. Dattilio \& A. Freeman (Orgs.), Terapia cognitiva com crianças e adolescentes: manual para a prática clínica (pp. 161-178, M. R. Hofmeister, Trad.). Porto Alegre: Artes Médicas. (Original publicado em 1996)

Kellog, N. D. \& Menard, S. W. (2003). Violence among family members of children and adolescents evaluated for sexual abuse. Child Abuse \& Neglect, 27, 1367-1376.

Koller, S. H. (1999). Violência doméstica: Uma visão ecológica. Em Violência doméstica (pp. 32-42). São Leopoldo: AMENCAR.

Koller, S. H. \& De Antoni, C. (2004). Violência intrafamiliar: Uma visão ecológica. Em S. H. Koller (Org.), Ecologia do desenvolvimento humano: Pesquisa e intervenção no Brasil (pp. 293-310). São Paulo: Casa do Psicólogo.
Koller, S. H., Moraes, N. A. \& Cerqueira-Santos, E. (2005). Perpetradores de abuso sexual: Um estudo com caminhoneiros. Relatório Técnico de Pesquisa. World Childhood Foundation, Porto Alegre, RS.

Kristensen, C. H., Oliveira, M. S. \& Flores, R. Z. (1999). Violência contra crianças e adolescentes na Grande Porto Alegre: pode piorar? Em AMENCAR (Org.), Violência doméstica (pp. 104117). São Leopoldo

Mannarino, A. P., Cohen, J. A. \& Berman, S. R. (1994). The children's attributions and perceptions scale: a new measure of sexual abuse-related factors. Journal of Clinical Child Psychology, 23(2), 204-211.

Mattos, G. O. (2002). Abuso sexual em crianças pequenas: peculiaridades e dilemas no diagnóstico e no tratamento. Em D. C. A. Ferrari \& T. C. C. Vecina (Orgs.), O fim do silêncio na violência familiar (pp. 174-200). São Paulo: Editora Agora.

Mayer, L. R. (2003). Rede de apoio social e representação mental das relações de apego de meninas vítimas de violência doméstica. Tese de Doutorado, Universidade Federal do Rio Grande do Sul, Porto Alegre.

Osofsky, J. D. (1995). The effects of exposure to violence on young children. American Psychologist, 50(9), 782-788.

Rouyer, M. (1997). As crianças vítimas, conseqüências a curto e médio prazo. Em M. Gabel (Org.), Crianças Vítimas de Abuso Sexual (pp. 62-90). São Paulo: Summus Editorial.

Saywitz, K. J., Mannarino, A. P., Berliner, L. \& Cohen, J. A. (2000). Treatment for sexually abused children and adolescents. American Psychologist, 55(9), 1040-1049.

Thomas, M., Eckenrode, J. \& Garbarino (1997). Family sexual abuse. Em J. Garbarino \& J. Eckenrode (Orgs.), Understanding abusive families: an ecological approach to theory and practice (pp.114 - 130). San Francisco: Jossey-Bass Publishers.

Zavaschi, M. L. S., Telelbom, M., Gazal, C. H. \& Shansis, F. M. (1991). Abuso sexual na infância: um desafio terapêutico. Revista de Psiquiatria, 13(3), 136-145.

Recebido em 01.06.2005

Primeira decisão editorial em 29.07.2005

Versão final em 04.08.2005

Aceito em 26.10.2005 